\title{
LOS MEDIOS DE COMUNICACIÓN COMO CONTROL DEL PODER POLÍTICO
}

\author{
JORGE DE ESTEBAN \\ Catedrático de Derecho Constitucional \\ Universidad Complutense
}




\section{SUMARIO}

I. INTRODUCCIÓN. II. EL «JANISMO" DE LOS MEDIOS DE COMUNICACIÓN DE MASAS. III. EL CONTROL DE LOS MEDIOS POR EL PODER POLITICO. IV. EL CONTROL DEL PODER POLITICO POR LOS MEDIOS. V. LA FUNCIÓN EFECTIVA DE LOS MEDIOS. VI. CONCLUSIÓN. 


\title{
LOS MEDIOS DE COMUNICACIÓN COMO CONTROL DEL PODER POLÍTICO
}

\author{
POR \\ JORGE DE ESTEBAN
}

\section{INTRODUCCIÓN}

«En nuestros días un ciudadano a quien se oprime no tiene más que un medio para defenderse y es dirigirse a la nación entera y, si se mantiene sorda, al género humano; no tiene más que un medio para hacerlo y consiste en la prensa... La prensa es por excelencia el instrumento democrático de la libertad" ' 1 . Así se expresaba, hace algo más de un siglo, ALEXIS DE TOCQUEVILLE, al realizar su genial análisis de la democracia americana, tras una estancia de poco más de un año en los Estados Unidos. Diagnóstico que, por lo demás, todavía sigue siendo válido en la actualidad, con la única salvedad de que habría que sustituir el término convencional de «prensa" por el más amplio de "medios de comunicación de masas", en razón de los avances tecnológicos que se han producido.

Sea lo que fuere, el resultado continúa siendo el mismo: los medios de comunicación y, en especial, la prensa diaria, la radio y la televisión, aparecen teóricamente, en nuestras sociedades democráticas modernas, como el último reducto de la libertad de los ciudadanos y, por tanto, como un instrumento decisivo para el control del poder político.

1 Tocqueville, A. DE, De la democracia en América, Editorial Aguilar, tomo I, Madrid, 1989. 
La razón de tal axioma es muy simple: una sociedad únicamente será auténticamente democrática en la medida en que todos sus miembros puedan acceder al conocimiento de todo lo que sucede en ella. De este modo, cabría afirmar que todo gobernante totalitario se caracteriza especialmente por una cosa: por privar a sus súbditos del conocimiento.

Por el contrario, en las sociedades democráticas, que están integradas por ciudadanos, el conocimiento de lo que sucede en su seno no es sólo una necesidad práctica, sino incluso un derecho fundamental a estar informado, puesto que no se puede estar fuera del tiempo ni separado de los demás. La soberanía, fuente de todo poder político, exige que su titular natural que es el pueblo, esto es, el conjunto de todos los ciudadanos, pueda acceder en todo momento al conocimiento de lo que acontece en todos los ámbitos de la sociedad. En efecto, como señalan dos autores franceses, «el estatuto de la información descansa en Occidente en la filosofía y la revolución del siglo XVIII, es decir, en una concepción y en una política que ponen en el centro al individuo y a la democracia. En nombre de la libertad y de la igualdad de los individuos, la información, toda la información, debe ser accesible a todos los ciudadanos, como medio de conocimiento de la realidad y de actuación sobre ella. Es indisociable de la idea de igualdad y de universalidad. Es lo que se llama «un derecho». Es el principio que ha permitido la batalla, renovada cada dia, de la prensa escrita desde hace dos siglos. Y es una concepción esencialmente política que no tiene más legitimidad que un sistema de valores, propio de una cultura, la occidental» 2 .

Pues bien, el instrumento esencial e indispensable para que los ciudadanos alcancen ese conocimiento necesario es el que constituyen los medios de comunicación. Sin ellos, en las sociedades de nuestros días, ya no es posible gobernar ni ejercer la oposición, aprender o enseñar, trabajar o practicar el ocio, comprar o vender.

Cabe afirmar así que vivir en sociedad consiste sobre todo en comunicarse. Ciertamente, un grupo puede llegar mismamente a prescindir de intercambios de bienes materiales, pero si no intercambia informaciones, ideas o emociones, desaparecerán los vínculos sociales, puesto que ya no habrá nada en común entre sus miembros.

Tal necesidad tiene un alcance general en todos los ámbitos de una comunidad, pero en lo que respecta a su forma de organización política, la

2 Gallouedec-Genuys, F. Y Lemoine, P., La informatización, riesgos culturales, Mitre, Barcelona, 1986, pág. 86. 
importancia es aún mayor. Precisamente las democracias se diferencian de las demás formas de gobierno porque en ellas la comunicación política, es decir, la que se refiere a los gobernantes y a los gobernados, debe ser totalmente transparente. Lo que diferencia a la autocracia de la democracia consiste sobre todo en la «visibilidad»; en la publicidad y en el rechazo de los arcana imperii. No fueron otros los principios en que se basó la modernidad, considerada como «iluminismo» o «ilustración», frente al tradicional obscurantismo de la autocracia. Por tanto, no es extraño, que el término ruso de glasnost o transparencia fuese uno de los primeros slogans que se adoptaran en el intento de la perestroika, fletada por GoRvaCHOV y que dio lugar al tránsito de la dictadura a la democracia que conocen en la actualidad los países del este de Europa.

Conocimiento, comunicación y transparencia son, pues, los tres pilares en que deben descansar la actuación y la justificación de los medios de información en toda democracia. Sin embargo, el inmenso poder que es consustancial a la utilización de los mismos conduce a la constatación de que, como ocurre con el dios Jano, poseen también dos caras de significado distinto. Esto es, una, que aparece como un privilegiado instrumento de control de la sociedad por parte del poder político y, otra, que representa una poderosa arma de control del poder político por parte de la sociedad. En definitiva, esta naturaleza bifronte de los medios de comunicación, visible siempre en los sistemas democráticos, constituye así el objeto central de esta exposición.

\section{EL «JANISMO» DE LOS MEDIOS DE COMUNICACIÓN DE MASAS}

En efecto, aún siendo los medios siempre la misma cosa, pueden servir para la obtención de dos metas claramente contra puestas: por un lado, para consolidar y ampliar el poder de los gobernantes hasta para convertirlo incluso en absoluto o totalitario. $Y$, por otro, para ejercer una labor de información y control, de seguimiento y vigilancia del poder político, denunciando sus abusos. Como la lengua de Esopo, los medios pueden servir tanto para lo peor como para lo mejor.

Por supuesto, desde un plano idealista, y tal vez utópico, la misión genuina de los medios en los regímenes democráticos debería ser únicamente la segunda. Mientras que en los regímenes dictatoriales o autoritarios la función de los mismos se limita exclusivamente a la primera. Sin embargo, si tenemos en cuenta que la naturaleza del poder político es siempre la 
misma, ya que el poder tiende a abusar del poder y la única diferencia entre las dictaduras y las democracias radica en que en éstas existen controles institucionalizados para evitar dicho abuso, habría que concluir afirmando que ni siquiera en estas últimas se puede erradicar del todo dicha tendencia. En unas y otras, el dirigente político aspira sobre todo a persuadir al público en general de sus convicciones, de sus certidumbres y de la utilidad de sus decisiones. El político, en consecuencia, tiene necesidad de propaganda más que de información ${ }^{3}$.

No cabe más remedio, por tanto, que sostener que el «janismo" de los medios que acabo de señalar es un fenómeno que ineludiblemente existe, en mayor o menor medida, en todas las democracias. Las cuales pueden definirse, desde el punto de vista que estamos analizando, como aquellos regímenes en que existe un pluralismo informativo que, como mínimo, que ciertos medios de comunicación puedan ejercer esa tarea de control y vigilancia del poder. Circunstancia que evidentemente no se produce en los regímenes dictatoriales o totalitarios, en los que los medios en su conjunto no tienen más que una cara, la cara del poder, estando exclusivamente a su servicio.

Es más: en este caso, la información, que es la mercancía que expenden los medios, se convierte, como he dicho, en pura propaganda, de tal modo que en las actuales sociedades no es posible la implantación de un régimen de este tipo si no se cuenta con la colaboración de los medios. Es sabido que una de las causas decisivas del rápido acceso del III Reich al poder, y posteriormente de su arraigamiento, fue la utilización que Hitler y sus secuaces hicieron de la radio como medio de adoctrinamiento de las masas. Y es igualmente conocido que la mejor garantía del triunfo de un golpe de Estado o revolución en nuestros días, pasa por la conquista inicial de la televisión y, más tarde, de la radio y la prensa escrita. De esta forma, si el régimen es totalitario quedan en manos del Gobierno todos los medios de comunicación, y si es únicamente autoritario permitirá que alguno de ellos sean privados, pero, en todo caso, con el establecimiento de la censura y de otras medidas restrictivas de la libertad de expresión que comprenden una amplia panoplia.

Con todo, esta ambición de controlar los medios, como he dicho, no es privativa de los países dictatoriales o totalitarios, sino que el hecho nuevo, por decirlo así, consiste en el «descubrimiento» de que también se ejerce mejor el mando en las democracias con la creación "forzada" de un «consenso» que favorezca la obediencia. La novedad consiste justamente

${ }^{3}$ Cfr., Chamoux, J.P., Droit de la communication, P.U.F., Paris, 1994, pág. 118. 
en que se llega al convencimiento de que sólo dicho consenso global facilita el mando total, objetivo para el cual es clave la información, por lo que ésta debe ser poseída, controlada y orientada a través de los medios, a fin de que nazca de abajo a arriba lo que se quiere obtener desde arriba.

Como ha escrito DANIEL BELL «el punto crucial de toda sociedad postindustrial lo constituye el hecho de que el conocimiento y la información llegan a convertirse en recursos estratégicos y transformadores de esa sociedad, igual que el capital y el trabajo lo han sido en la sociedad industrial'» ${ }^{4}$. Se llega entonces a la convicción de que los medios no pueden ser ajenos al concepto del poder político, del cual constituyen un aspecto y, por decirlo así, una terminal destinada a su perpetuación a través del mantenimiento del consenso global.

En definitiva, el poder de informar, concebido de este modo, no significa otra cosa sino el poder de organizar el pensamiento de la gente, de condicionarlo y de dirigirlo con el exclusivo fin de servir al poder. Lo cual no es sorprendente, porque como recuerda GALBRAITH el poder máximo consiste en la organización de los pensamientos ${ }^{5}$. De tal suerte, el control de los medios en las democracias por parte de los gobernantes se explica por el deseo de conservar el poder político, una vez obtenido a través de las urnas, ya que facilita, como dijimos, la obediencia de los ciudadanos. Sin embargo, esta tendencia dirigida al control de los medios debe coexistir más o menos en los regímenes democráticos con la otra cara de los mismos, que se basa en el pluralismo informativo y en el hecho de que algunos medios independientes luchan por controlar al poder con el fin de impedir su abuso. Por consiguiente, una vez expuestas ambas tendencias, paso a exponer ahora las peculiaridades de cada una de ellas.

\section{EL CONTROL DE LOS MEDIOS POR EL PODER POLÍTICO}

Como digo, es claro que en un sistema democrático el indispensable pluralismo informativo impide, a diferencia de lo que sucede en los regímenes

4 BELL, D., "La revolución tecnológica de las comunicaciones y sus consecuencias", Harvard-Deusto Business Review, primer trimestre de 1981, pág. 38.

5 Cfr., Galbraith, J.K., La anatomia del poder, Plaza-Janes, Barcelona, 1984, pássim y, especialmente, págs. 237 y ss. 
autoritarios o totalitarios, que el poder político se sirva, en forma de monopolio, de los medios de comunicación de masas. Ahora bien, de manera consciente o «inconsciente", los gobernantes siempre trataran de controlar al mayor número de ellos, por la sencilla razón de que saben perfectamente que los hechos cambian objetivamente de naturaleza cuando llegan a ser conocidos por la opinión pública. En tal supuesto, lo determinante es la suma de los hechos más su conocimiento público, es decir, ese conocimiento adicional es lo que modifica la naturaleza de tales hechos. De ahí que cuando no sean legales, éticos o políticamente oportunos, unidamente se podrán evitar, corregir o sancionar si llegan a ser públicamente conocidos.

Según señala GONZÁLEZ SEARA, «el escándalo público, normalmente proscrito en los sistemas totalitarios, no es otra cosa que la publicidad tardía de actos que se han mantenido ocultos, a pesar de su ilegalidad o inmoralidad, porque de haberse hecho públicos a tiempo, no hubieran podido seguir adelante" ${ }^{6}$. Ante semejante certidumbre, los gobernantes tienden a considerar que la información es un privilegio suyo que no tienen por qué compartir en muchos casos con nadie, al igual que si se tratase de un coto privado de caza. Actuando así ignoran o pretenden ignorar que el único depositario de la información es la sociedad, integrada por ciudadanos que son titulares del derecho fundamental a la información.

En consecuencia, el poder político, aspirando al control de los medios de comunicación, trata de conseguir, a través de los mismos, los siguientes objetivos. En primer lugar, intenta ocultar toda información que no le sea favorable, para lo cual impide el acceso de los periodistas a cualquier actividad política o administrativa que pueda poner en tela de juicio su gestión. En segundo lugar, favorece la manipulación de la información emitida en beneficio propio, revalorizando los aspectos positivos y silenciando los negativos de la misma. En tercer término, presiona para que los medios jerarquicen las noticias sobre los acontecimientos de acuerdo con la valoración oficial. Por último, favorece la tendencia a difundir programas o noticias deformadoras de la opinión pública, con el fin de mantener distraídos a los ciudadanos con asuntos estupidizantes, morbosos o de entretenimiento banal. En otras palabras, se trata de actualizar el viejo panem et circense conocido ya desde la época de la Roma clásica ${ }^{7}$.

6 González Seara, L., “Información democrática y razón de Estado», Diario-16, 14 de mayo de 1993, pág. 14.

7 DE Esteban, J., Por una comunicación democrática, Fernando Torres-Editor, Valencia, 1976, págs. 55 y ss. 
Digámoslo claramente: esta tendencia no es ajena a ningún Gobierno democrático, aunque ciertamente será más o menos decisiva según sean las convicciones democráticas del mismo y según sea también, en su caso, la regulación jurídica que exista de los medios. Pero ineludiblemente esta tendencia planeará siempre sobre el poder político, por la sencilla razón de que todo Gobierno aspira a gobernar con el menor número posible de resistencias y éstas se neutralizan con mayor eficacia si se dispone del control de los medios de comunicación.

Aceptando, por tanto, que el objetivo deseado por todo Gobierno es el que acabo de describir, lo que se requiere ahora es proceder a la enumeración de los instrumentos que se utilizan para conseguirlo. Su descripción se hace desde una perspectiva general, por lo que conviene advertir que sería necesario establecer las matizaciones pertinentes en cada caso. Sin embargo, en lo que respecta al supuesto español cabe afirmar que concurren en él la mayoría de esos instrumentos de control, según comprobaremos enseguida.

En primer lugar, todo Gobierno, si no se le impide, tratará de disponer en su provecho de los medios de comunicación que sean de titularidad pública, confundiendo así los intereses del Estado o de la sociedad con sus propios intereses partidistas. Ahora bien, los tres medios de comunicación de masas que estamos considerando - prensa diaria, radio y televisión- no tienen idéntica audiencia entre los ciudadanos y, por consiguiente, los esfuerzos de los diversos Gobiernos en pos de su control conocerán diversos grados. En efecto, limitándonos al caso español actual, cabe afirmar que según una encuesta realizada por el Centro de Investigaciones sobre la Realidad Social (CIRES), en diciembre de 1992, los españoles reconocen que sus opiniones, su estilo de vida, sus hábitos de consumo y moda, están regidos por los medios de comunicación de masas. Sin embargo, la audiencia y, por tanto, la influencia de los mismos no es igual en los tres supuestos señalados.

Según dicha encuesta, se confirma que un $98 \%$ de los españoles mayores de 18 años ve asiduamente la televisión; un 67\% escucha la radio; y menos de un $49 \%$ lee en alguna ocasión un diario, incluidos los deportivos ${ }^{8}$. Por consiguiente, dejando al margen las peculiaridades técnicas de cada uno de estos medios, las cuáles obligan a una mayor o menor intervención del Estado respecto de sus soportes de difusión, es evidente que los

s Cfr. CiREs, La realidad social en España, 1992-93, Ediciones B, Barcelona, 1994, págs. 277 y ss. 
Gobiernos intentan controlar al máximo la televisión, menos la radio y, más difícilmente, la prensa diaria que normalmente es de titularidad privada.

En lo que respecta concretamente a la televisión, es posible afirmar que en la mayoría de los países europeos occidentales suele coexistir una televisión de titularidad pública con otra de propiedad privada ${ }^{9}$. Las líneas tendenciales del funcionamiento de este medio, sin que podamos entrar en matizaciones, se basan en el mayor o menor control o influencia de los Gobiernos, de forma directa, sobre las cadenas de titularidad pública y, de forma indirecta, según diversas vías, sobre las privadas.

Un ejemplo paradigmático de esta tendencia de los Gobiernos a utilizar en su propio interés la televisión de titularidad pública, nos lo ofrece la Italia actual. Después del derrumbe de la denominada I República y de la desaparición de la tradicional clase política, como consecuencia del activismo de los jueces en los procesos denominados como mani pulite, el magnate de la televisión privada, SILVIO BERLUSCONI, capitaneando a la "nueva" clase política, se convirtió en el actual Presidente del Gobierno.

De este modo, se ha impuesto en este país, de forma exacerbada, lo que se ha dado en llamar como «telecracia», en tanto que novedosa forma de gobierno de nuestras actuales sociedades. Sin que sepamos todavía a dónde conducirá tan inquietante fenómeno, el hecho es que podría consistir en un sutil método del autoritarismo y que, por el momento, nos ilustra sobre las dos hipótesis que expusimos antes. Esto es, el caso italiano nos muestra como el empleo de la televisión puede servir tanto para conquistar el poder como para mantenerlo a la luz de los siguientes hechos.

Por una parte, Berlusconi, utilizando sus tres cadenas propias de televisión, pudo organizar en el espacio de un mes una estructura organizativa de clubs políticos, unificados bajo el futbolístico nombre de Forza Italia -no en vano es también propietario del club de fútbol Milán-, que le sirvió para ganar dos sucesivas elecciones, nacionales y europeas. $Y$, por otra, se debe señalar que una de las primeras medidas adoptadas por su Gobierno fue la de reorganizar las tres cadenas públicas de la $\mathrm{RAl}$, en razón de que «no se puede permitir que sean críticas con el Gobierno". Es más, la utilización partidista de la RAl por parte del Gobierno Berlusconi llegó hasta el punto de

9 Ver, por ejemplo, para mayor detalle, Regourd, S., La télévision des Européens, La Documentation Francaise, Paris, 1992, págs. 40 y ss. 
transmitir spots anunciando sus logros políticos ${ }^{10}$. Sin embargo, las protestas generalizadas ante este abuso obligó al Gobierno a retirar tal género de propaganda. Ni siquiera en una novela de ciencia-ficción se podía haber llegado tan lejos en este intento de controlar de forma tendenciosa el medio de comunicación más influyente en nuestras sociedades actuales.

Con todo, este fenómeno, sin semejante crudeza, se da también parcialmente en otros países europeos y, especialmente también, en el nuestro. Los Gobiernos controlan, más o menos directamente, la televisión de titularidad pública y tratan de influir igualmente, de forma indirecta, en la televisión privada, casi siempre en manos de grupos económicos importantes afines a su política o que buscan el favor del príncipe...

Tendencia que seguirá manteniéndose mientras que la televisión por cable o por satélite no llegue a generalizarse, ya que las emisoras de televisión de alcance nacional siguen siendo escasas y, por tanto, son más fáciles de controlar por parte de los diversos Gobiernos.

De ahí que el control de la radio, a causa de su mayor pluralismo, sea menor que en el caso de la televisión, pero evidentemente también existe, tanto directamente, a través de las emisoras de titularidad pública, como, de forma indirecta, respecto a las privadas, cuya concesión se hace en favor de grupos afines al Gobierno. En cualquier caso, es posible que existan, según los diferentes países, emisoras de radio que sean mucho más independientes que en el supuesto de la televisión ${ }^{11}$.

En lo que respecta a la prensa diaria es indudable que los regímenes democráticos no permiten la existencia de periódicos de titularidad pública o estatal, ya que son de naturaleza privada y, en consecuencia, resulta más difícil, en principio, su control directo por los Gobiernos. Además, su menor difusión y audiencia, en comparación con la de los otros medios, parece que no debería incitar tanto la voracidad del poder político.

No debería en teoría, pero en la práctica es también así. En efecto, a pesar de su menor difusión, la prensa escrita continúa poseyendo una importancia capital en la crítica y en el control del poder. Especialmente por dos razones: por un lado, porque su influencia afecta directamente a las élites de la sociedad, que son las que la leen preferentemente $y$, por otro, porque

10 Ver La Repubblica, 8 de agosto y ss.

11 Ver, por ejemplo, GARCía LlOVET, E., El régimen jurfdico de la radiodifusión, Ed. Marcial Pons, Madrid, 1991. 
indirectamente llega también al gran público desde el momento en que muchos de sus contenidos son recogidos por la radio y la televisión.

Se trata, consecuentemente, de un medio a la larga más poderoso intelectualmente que los otros dos y no es extraño por ende que los Gobiernos intenten también controlar de algún modo el mayor número posible de periódicos. Las vías para conseguirlo son esencialmente dos: una jurídica y otra económica. La primera, que también puede ser aplicable a la radio y a la televisión, consiste en la aprobación de normativas restrictivas que impidan u obstaculicen el ejercicio de una plena libertad de información.

De este modo, en aras de la democracia, no es sorprendente que se siga manteniendo que la mejor ley de prensa es la que no existe. Aunque cabe utilizar, en cambio, otros instrumentos jurídicos, como el Código Penal, para tipificar como delitos o faltas determinadas conductas $u$ opiniones periodísticas. En otro orden de cosas, cabe mencionar igualmente la creación de normas que favorezcan la concentración de empresas periodísticas, situación que siempre es más manejable por el poder que los reinos de Taifas informativos.

La segunda vía, de naturaleza económica, es mucho más sinuosa, pero probablemente mucho más eficaz. Es sabido que ante la prácticamente total libertad de fundación de periódicos, se yergue, en cambio, al igual que una montaña difícilmente franqueable, el enorme costo económico que representa hoy el mantenimiento de un diario. Tal circunstancia, explicable por la escasa tasa de lectura, por la huida de la publicidad a la radio y a la televisión y por los cuantiosos gastos salariales que comporta una nutrida redacción de profesionales, no permite que cualquiera pueda fundar un nuevo periódico, al menos de alcance nacional. En consecuencia, son fundamentalmente los grandes grupos económicos, que necesitan llevarse bien con el poder, los que pueden mantener diarios nacionales de forma competitiva.

Sin embargo, cuando, a pesar de estos obstáculos, algún diario independiente logra sobrevivir con enormes esfuerzos económicos, el poder político dispone también de una amplia gama de medidas para poder controlarlo o acallarlo, ya que la mayoría de la prensa escrita necesita de la ayuda estatal para lograr subsistir. La discriminación en la publicidad institucional o en la información gubernamental, el aumento intencionado del precio del papel-prensa, la supresión de beneficios postales, la compra teledirigida de un paquete mayoritario de acciones de la empresa a cargo de testaferros encubiertos del Gobierno, son algunas de las varias medidas que éste puede utilizar en su intento de controlar o acallar algún incómodo diario independiente. No creo que haga falta señalar ejemplos concretos de lo que ha 
sucedido en nuestro país a este respecto y en el que incluso se ha llegado a controlar el teléfono de ciertos periodistas.

Parece obvio, en consecuencia, que la mejor manera de lograr sobrevivir en el ámbito de la prensa diaria, consiste bien mantener una línea editorial favorable al Gobierno, bien en integrarse en grupos multimedia de saneadas economías. Aunque evidentemente lo óptimo es, como ilustra algún ejemplo actual, adoptar ambas posiciones a la vez.

En otro orden de cosas, también se logra controlar de algún modo la información que suministran los medios y, especialmente, la prensa escrita, a través del monopolio de agencias estatales de prensa, las cuales se encargan ya de jerarquizar, ya de ocultar o manipular, las informaciones que los diarios se ven obligados a comprar.

Como se ve, los Gobiernos en los sistemas democráticos tampoco están exentos de la tentación de controlar a los medios de comunicación, disponiendo a tal fin de un extenso abanico de posibilidades si es que caen en dicha tentación. Además siempre queda el recurso, si no es posible controlar a la prensa independiente de forma global, de "comprar" puntualmente, por la vía espúrea que sea, a algunos de los periodistas que trabajan en ella. Se atribuye así a un político la frase de «que no tengo suficiente dinero para comprar un periódico, pero sí el necesario para comprar a varios periodistas».

Es más: la tentación señalada será tanto más fuerte cuanto mayor fortaleza y mayoría electoral posea un Gobierno y cuanto más tiempo permanezca en el poder. La mejor manera de contrarrestar tan perniciosa tendencia en nuestras democracias radica, por supuesto, en el ejercicio de la alternancia periódica en el poder y en la existencia de eficaces controles juridicos, políticos e institucionales del poder político. Pero si semejantes mecanismos tampoco funcionan, entonces la última trinchera de la defensa de la democracia no es otra, en los regímenes con pluralismo informático, que la existencia de algunos medios de comunicación independientes del poder que sea capaces de controlarlo. A ello vamos a dedicar la segunda parte de esta exposición.

\section{EL CONTROL DEL PODER POLÍTICO POR LOS MEDIOS}

La importancia de la información como arma política es tan antigua como la humanidad, pero aumentó considerablemente desde el momento en 
que la técnica permitió su más amplia difusión. Ya el invento de la imprenta fue decisivo para el surgimiento del Renacimiento, de la Reforma y del pensamiento liberal que desembocó en la Revolución Francesa.

Sin embargo, será con la aparición de la prensa escrita cuando la información que ella comportaba adquirió un papel decisivo en el nacimiento de los regímenes democráticos. No puede sorprender así que BURKE, a fines del siglo XVIII, la definiera con una expresión que desde entonces ha conocido una gran fortuna, esto es, como el «cuarto poder», completando así los tres poderes clásicos del Estado expuestos por MONTESQUIEU. Pero la general adopción de esta denominación, utilizada también ampliamente en nuestros días, no debe confundirnos sobre su validez, la cual es extensible hoy también a la radio y a la televisión. $Y$ no debe confundirnos porque los medios de comunicación unidamente podrían ser conceptuados como el "cuarto poder" en aquellos países en que todos ellos fuesen monopolio del Estado.

Utilizar, por el contrario, este término en las democracias actuales, después de lo que hemos visto, es un craso error por la sencilla razón de que tal poder in totum ni lo posee por completo el Estado -el Gobierno- ni tampoco funciona, en sentido inverso, como un instrumento unitario o monolítico de todos los medios de comunicación frente al poder político. Se explica la difusión de semejante leyenda tanto por el ejemplo americano, puesto que en los Estados Unidos «en principio» la mayoría de los medios son privados, como por el ejemplo que suministra el inicio de la prensa escrita en Europa cuando surgieron los primeros diarios gracias a la iniciativa privada. Se creó así el mito del fabuloso poder de la prensa, susceptible de crear o derribar Gobiernos a su antojo, hasta el punto de que BALZAC, aterrorizado por ese naciente poder incontrolado, llegó a decir en 1840 que «si no existiera la prensa, no habria que inventarla» ${ }^{12}$.

De todas formas, esta visión se acabó convirtiendo en un tópico y, como la mayoría de los lugares comunes, no refleja enteramente la verdad. La realidad de nuestros días, como vengo exponiendo, consiste más bien en el «janismo» de los medios y, por consiguiente, no existe en las democracias un cuarto poder que esté totalmente a favor o en contra de los otros poderes del Estado. Sin embargo, el hecho es que el poder político siempre siente la tentación de controlar, de manipular, de ocultar o, cuando menos, de

12 Cfr. BALLE, F., “Información y poder» en VV.AA. El futuro del discurso del poder, Senado, Madrid, 1989, pág. 48. 
influir, directa o indirectamente, la información que suministran los medios de comunicación social.

Como ha expuesto LUIS RACIONERO «la información es el recurso vital de nuestro tiempo: así como en la economía agrícola el poder se apropiaba y controlaba el excedente alimentario, y tras la revolución industrial el poder controló el capital, ahora, tras la revolución cibernética, el excedente de información es lo que da poder. La información es el recurso escaso de este momento en las sociedades opulentas, donde el dinero es abundante; la lucha por el poder es la lucha por el poder de los medios de comunicación, su generación y su diseminación» ${ }^{13}$.

En definitiva, es el pluralismo informativo, consustancial a los sistemas democráticos, lo que impide que la larga mano del poder llegue a controlar la totalidad de los medios, pues aunque logre conseguirlo en parte respecto a la radio y a la televisión, siempre le resultará más difícil, por las razones apuntadas, su dominio sobre la prensa escrita.

Por lo tanto, el eventual control del poder político que pueden ejercer los medios de comunicación hay que residenciarlo sobre todo en la prensa diaria o, mejor dicho, en la prensa escrita que sea auténticamente independiente. Sólo la que goce de esta cualidad, sea cual sea el partido que gobierne, podrá desempeñar realmente la función de vigilancia del poder político. Para ello, es decir, para que se pueda afirmar su independencia es indispensable la concurrencia de varios requisitos que paso a exponer sucintamente y que se refieren, en especial, a la prensa diaria.

De entrada, la empresa periodística debe gozar de la suficiente autonomía económica para no tener que depender del poder político o de sus testaferros. La mayor diversificación y división de los accionistas de la empresa es siempre más seguro que el que ésta posea uno o pocos dueños. Es más, también es necesario, en cualquier caso, que se garantice la transparencia de sus propietarios, a fin de evitar todo tipo de sospecha sobre los posibles intereses partidistas de los mismos.

En segundo término, es igualmente indispensable que los periodistas que trabajen en un medio gocen de unas garantías que se justifican más que por meras razones corporativas, por asegurar la defensa de los usuarios del medio. La existencia de un Estatuto de la Redacción, de la cláusula de conciencia y del secreto profesional con el fin de no estar obligados a revelar sus

13 Racionero, L., «Los intelectuales y el poder», EL MUNDO, 9 de agosto de 1994, pág. 4. 
fuentes de información, son elementos imprescindibles para lograr la independencia del medio.

Por último, si como es lógico los verdaderos "dueños" de un diario son los que lo compran y lo leen voluntariamente, se requiere también que los que trabajen en él, comenzando por el director, sean auténticos profesionales. Porque lo que diferencia al profesional del diletante en cualquier oficio, no es sólo la suma de conocimientos especializados de tipo técnico-cultural que se posea, sino sobre todo el conjunto de valores que permiten tener indisolublemente unidos los intereses propios con el interés general, de acuerdo con una ética profesional. De este modo, como señala FRANCIS BALLE, "se puede reprochar a un periodista que trabaja en un periódico que se considera independiente que no realice un esfuerzo de distanciamiento o que transgreda una norma moral que es exactamente la misma que debe respetar todo maestro y que consiste en no decir nunca más de lo que se sabe y en no presentar jamás una opinión como un hecho» ${ }^{14}$.

Por supuesto, el cumplimiento de los requisitos expuestos no garantiza de forma automática y absoluta la independencia de un medio informativo, pero no cabe duda de que sin ellos resulta imposible mantener que un medio sea independiente. De ahí que, en todos los países, sean escasos los periódicos que gozan de semejante cualidad, la cual debería ser una condición sine qua non para cumplir con la función tradicional de la prensa, consistente en informar de todo libremente. Si la democracia se basa en la libertad y en la igualdad de los ciudadanos, la información, toda la información, debe ser accesible a todos ellos con el fin de que se conozca la realidad y de que se pueda actuar sobre ella.

Ahora bien, esta función simplemente informativa de la prensa, sería unidamente suficiente en una democracia en la que la regla de la transparencia fuese minuciosamente respetada por los gobernantes y por las instituciones del Estado. Pero cuando no ocurre así, cuando se abusa del poder, cuando no funcionan como debieran las instituciones del Estado, cuando la corrupción y la ausencia de una ética pública se convierten en un estilo de gobernar, entonces la prensa independiente puede ejercer también el papel de contrapoder u oposición, supliendo la función que tendrían que cumplir otras instancias. Ante la inoperancia de otros controles institucionales, la

14 BALLE, F., «Información y poder» en VV.AA. El futuro del discurso del poder, op. cit., pág. 56. 
prensa puede acabar convirtiéndose en la última señal de alarma del mal funcionamiento del sistema político y en la defensora de los valores democráticos de la sociedad.

El mítico periodista americano JOSEPH PULITZER describía así dicha función: "Somos una democracia y para conseguir que se ajusten a ella las conductas individuales, sociales, municipales, estatales y nacionales, el mejor medio es mantener informado al público de lo que sucede, porque no hay delito, no hay asunto, no hay ardid, no hay estafa y no hay corrupción que no puedan perdurar en el secreto" ${ }^{15}$. En consecuencia, la función de control del poder político por parte de la prensa, haciendo público lo secreto, representa la mayor garantía de la democracia, pero unidamente la pueden desempeñar obviamente los medios que sean auténticamente independientes.

Por lo demás, es necesario subrayar también que dicha función difícilmente se podrá ejercer si nos atenemos a la forma convencional de obtener información. La denuncia de la opacidad del poder, de sus abusos, de la desnaturalización de las instituciones, exige medios especiales para lograr la información adecuada. A tal fin cabe distinguir cuatro procedimientos especiales que la prensa independiente utiliza para denunciar dichos excesos.

En primer lugar, a través del llamado "periodismo de investigación», esto es, de la dedicación de un equipo de periodistas consagrado a la averiguación de las conductas o hechos heterodoxos que se tratan de ocultar ${ }^{16}$. Los fundadores del semanario alemán Der Spiegel en Europa y los míticos periodistas americanos que desvelaron el asunto Watergate en los Estados Unidos, son los modelos más significativos que ilustran este método. Pero también en España han sido producto de esta forma de hacer periodismo los conocidos casos Filesa, Ibercorp, Rubio o Roldán, por no citar sino los ejemplos más conocidos.

En segundo lugar, esta función de denuncia de la prensa se ha de basar asimismo en la garantía del secreto profesional, reconocida en el artículo 20.1.d de nuestra Constitución y que permite servirse de fuentes anónimas o que deseen permanecer en el anonimato. Cuando el poder es

15 IreLAND, A., An adventure with a genius: Recollectios of Joseph Pulitzer, E. P. Dutton and Co., Nueva York, 1937, pág. 49.

16 Cfr. SANTOS, F., "El periodismo de investigación y las instituciones", EL PAIS, 28 de mayo de 1994, pág. 12. 
opaco y no transparente, la única forma de desvelar las conductas ilegales de los gobernantes o de las instituciones es recurrir a los soplos o informaciones confidenciales, que una vez verificados, deben ser publicados con la garantía del secreto.

En tercer lugar, contribuyen igualmente a consolidar esta función de la prensa independiente las denuncias que formulan los lectores por medio de sus cartas que, publicadas o no, vienen a certificar la credibilidad del medio al que se dirigen y que es el que leen voluntariamente.

Por último, se debe tener también en cuenta, a la hora de valorar esta función de los diarios independientes, la aportación de los intelectuales que colaboran en el medio. Con sus reflexiones criticas sobre los excesos de los gobernantes, sobre el irregular funcionamiento de las instituciones, sobre los ataques a los derechos y libertades fundamentales, contribuyen a controlar al poder político, erigiendo a la prensa independiente en el principal factor para que puedan surgir en la sociedad corrientes contrarias a todos los excesos del poder.

Con todo, cuando este tipo de prensa, por minoritaria que sea, se encuentra confrontada con el poder político, su actuación no es un camino de rosas. El poder, si no puede controlarla o silenciarla, tratará, a través de sus medios de comunicación propios o afines, de desprestigiarla utilizando diversos argumentos. Se la tacha así de «amarillista» o se la define como la nueva Inquisición, sin recordar que esta "Santa Institución" fue un instrumento del poder político, no un instrumento contra él, y que si se pudo utilizar fue precisamente porque entonces no había «prensa libre» 17.

Se afirma igualmente que el periodismo de investigación, en razón de la exclusiva que supone para el periódico en cuestión, no tiene más fin que el desvelar escándalos para aumentar sus cifras de venta. Pero con ello se viene a demostrar que la compra del diario no hace sino confirmar la necesidad de información veraz que deben poseer los ciudadanos en una democracia.

Se aduce a continuación que las fuentes anónimas no son nunca inocentes y que todo "delator" se halla motivado por sentimientos de rencor o venganza, de ambición o de intereses políticos particulares. Por supuesto, tal insinuación puede ser cierta, pero si la información es contrastada de

17 Ver, por ejemplo, las tesis de J. Leguina, «Reflexiones escocidas" en Cambio-16, 4 de julio de 1994, págs. 34 y ss. 
forma rigurosa y manifiesta una sólida veracidad, su publicación constituye un inestimable servicio a la democracia, con independencia de las motivaciones de los informantes anónimos o secretos.

En el mismo sentido, cuando la prensa independiente enjuicia conductas discutibles del poder político, éste intenta convencer de que la «opinión publicada" no es lo mismo que la opinión pública ${ }^{18}$. Se ha llegado a decir así, desde instancias oficiales, que «en España no hay un problema de corrupción, sino de 'opinión publicada'». En cualquier caso, la citada distinción no es más que un sofisma, puesto que si la opinión pública, concepto siempre un tanto gaseoso, llega a configurarse ostensiblemente, en parte se debe ciertamente a la influencia de los medios de comunicación, pero, al mismo tiempo, éstos, en el seno de un sistema de pluralismo informativo, no sólo la conforman, sino que también se basan en ella. Cuando el río suena, agua lleva y siempre existen medios para comprobarlo, como las cartas de los lectores o los sondeos que llevan a cabo los periódicos.

En definitiva, parece claro que existe siempre una contradicción entre lo que persigue el poder y lo que busca el periodismo independiente. Mientras que éste trata de difundir la veracidad de unos hechos contrarios a la ley o a los valores democráticos, la verdad no es nunca el objetivo prioritario del poder, sino más bien la acción y la consecución de resultados. Para ello se sive en muchas ocasiones del secretismo y de la desinformación, evitando de este modo las críticas adversas y responsables. Lo que viene a demostrar que la mejor vía para conseguir tal objetivo pasa por el control previo de los medios de comunicación.

De cualquier modo, la forma en que los medios pueden llegar a controlar al poder político consiste básicamente en el logro de tres objetivos: primero, en desvelar todas las actuaciones ilegales o abusivas del poder que se intenten mantener en la penumbra; segundo, en criticar las actuaciones del poder que no vayan en un sentido democrático o constitucional; y, por último, en actuar como vía de comunicación y enlace entre los diversos grupos de la sociedad, a fin de promover la cohesión social y las orientaciones de la política desde una perspectiva netamente democrática. Cuando se consiguen tales objetivos cabe hablar de un auténtico control del poder político por parte de la prensa independiente. Es cierto que los periodistas, en el ejercicio de esta importante función, pueden cometer excesos

18 Cfr., por ejemplo, Jiménez de PARga, M., La ilusión política, Alianza Editorial, Madrid, 1993, págs. 127 y ss. 
que no correspondan a la verdad y representen un perjuicio para los afectados. Pero tal riesgo debemos asumirlo, porque como señala, entre otros, RAWLS, constituye el precio que hay que pagar si queremos que realmente exista un sistema democrático con libertad de expresión. $Y$ además, siempre cabe, en tales supuestos, el recurso a procedimientos como el derecho de rectificación o, incluso, la vía judicial.

\section{LA FUNCIÓN EFECTIVA DE LOS MEDIOS}

Por lo demás, después de todo lo expuesto, sería una ingenuidad revalidar de forma absoluta el título que encabeza este trabajo, ya que en lugar de referirnos de modo general a «los medios de comunicación como control del poder político", habría que hablar más bien de "ciertos medios de comunicación como control del poder político".

Tal matización nos conduce a que reflexionemos brevemente sobre la función efectiva de los medios en nuestras sociedades actuales, partiendo de dos escenarios diferentes. El primero sería aquel que ofrecería una democracia en que la política estuviese presidida por la ética, en la que todas las instituciones funcionasen correctamente $y$ en donde existiese una transparencia absoluta en las actuaciones del poder, sin opacidad y secretismos.

En tal supuesto, que equivaldría a una especie de pórtico del mundo celestial, la función efectiva de los medios de comunicación consistiría exclusivamente en informar asépticamente, sirviendo de correa de transmisión entre los gobernantes y los gobernados. Sin embargo, no parece, por el momento, que tal hipótesis pueda llegar a imponerse en su virginal pureza.

De ahí que haya que recurrir a un segundo escenario integrado, con diferentes matices, por sistemas políticos teóricamente democráticos, pero en los que el poder continúa manteniendo zonas obscuras de actuación. Consecuentemente seguirá fomentando la desinformación de ciertos hechos $y$, lo que es peor, utilizará los medios de comunicación a su servicio como instrumentos para la obtención del ansiado consenso global, mediante técnicas manipuladoras con efectos engañosos o estupidizantes. Desgraciadamente, de no ponerse remedio, ésta es la orientación o tentación que en nuestras democracias seguirá manteniendo el poder de forma natural. $Y$ cuanto mayor sea la amplitud del control sobre los medios de comunicación, más cerca estaremos de un totalitarismo encubierto o, como se dice ahora, light. 
Es fundamental, por tanto, que ante semejante tenebrosa amenaza, los medios de comunicación desempeñen su eventual función democrática, que no es otra sino la de poner en práctica ese control del poder político, según lo que hemos expuesto. Pero, como es notorio, tal control será tanto más efectivo cuanto mayor sea el número de medios independientes que haya en la sociedad, circunstancia que, en gran parte, es algo que depende de la naturaleza de su titularidad.

De este modo, los medios de comunicación que en la actualidad son de titularidad pública, es decir, cierta radio y televisión, deberían regularse de tal manera que se impida su control directo por el Gobierno de turno. En sentido contrario, tampoco sería beneficioso para la democracia que estos medios se privatizaran totalmente, pues pasaríamos de su instrumentación por parte del poder político, a su entero control por los grandes grupos económicos que sólo persiguen beneficios y no el interés general.

La mejor garantía, en este sector de los medios, estriba, a mi juicio, en un sistema mixto de emisoras de titularidad pública y de emisoras de titularidad privada, dependientes ambas unidamente de un Consejo integrado por representantes de los usuarios, de los periodistas, de los grupos sociales y de las instituciones básicas de la sociedad. Modelo al que se acerca, por ejemplo, aunque no sea perfecto, el sistema británico de la BBC y que constituye un gran avance en relación con el que sufrimos en España ${ }^{19}$. La patológica y partidista obsesión de nuestros Gobiernos por mantener el control de la televisión está suponiendo que no se contenten con tener a su servicio a la RTVE, sino que también aspiran a influir, de un modo u otro, en las televisiones privadas.

De este modo, en nuestro país, como en algunos otros, la televisión se ha convertido en un poder político colosal que, como dice POPPER, es potencialmente el más importante de todos, "como si fuera Dios el que habla". De ahí que una democracia no pueda existir si no pone bajo control a la televisión, pues su esencia consiste en que no puede haber ningún poder político incontrolado ${ }^{20}$.

Y en lo que respecta a la prensa diaria, sector donde no existe la titularidad pública, es también indispensable que se garantice el pluralismo informativo. A tal fin el Estado debe llevar a cabo un sistema neutro de ayuda

19 Ver, por ejemplo, DE Esteban, J., Por una comunicación democrática, op. cit, pags. 109 y ss.

20 POPPER, K., La televisión, una mala maestra, su último ensayo, que aparecerá en breve. Las citas las he recogido de EL PAIS y LA VANGUARDIA, de 18 de septiembre de 1994. 
a este sector, sin perjuicio de que se reconozca el derecho a la competencia. Lo cual es garantía tanto de la libre elección de los lectores, como de la propia libertad de los periodistas, pues ésta se basa en la necesidad de una multiplicidad de los periódicos, en la posibilidad de cambio de uno a otro y en la suficiencia de los recursos del diario en que trabajen.

De esta suerte, la vigilancia del Estado democrático, a fin de garantizar el necesario pluralismo informativo, exige una regulación jurídica que impida el monopolio informativo tanto en manos públicas como privadas. La concentración abusiva de los medios en pocas empresas constituye en la actualidad el más grave peligro para la libertad informativa y, por tanto, para la democracia.

En tal sentido, se podría argüir que, guste o no, el fenómeno de la concentración de los medios es ya un hecho con el que hay que contar. Es más: algunos mantienen que en el presente caso español, es necesaria cierta concentración frente a la agresividad de los grandes multimedia internacionales que nos pueden invadir. Algo de ello esta pasando ya si tenemos en cuenta, por ejemplo, lo que ocurre en nuestra televisión privada. Aunque parezca inverosímil una de las cadenas existentes es en parte propiedad de un potente grupo italiano, lo que podría ser defendible en la lógica de la Unión Europea. Pero lo paradójico del asunto radica en que el dueño de dicho grupo no es, nada menos, que el actual Presidente del Gobierno de la República italiana...

Es urgente, por consiguiente, la aprobación de una ley que impida las concentraciones abusivas de los medios, porque de lo contrario el pluralismo informativo desaparecerá y, en consecuencia, la diversidad, fuente fundamental de la libertad de prensa, tenderá a favorecer los oligopolios informativos, acercándonos así a los regímenes autoritarios. Sin embargo, en lo que respecta a nuestro caso, no es esa la aspiración del Gobierno, sino precisamente la contraria, ya que interesadamente ha fomentado más bien la peligrosa concentración de medios en grupos afines.

Por lo demás, si no se remedia a tiempo este acechante peligro de nuestras democracias, es decir, si un número escaso de fuertes empresas multimedia llegasen a monopolizar la información, las consecuencias previsibles serian al menos dos.

Por una parte, desaparecería prácticamente la libertad de información, cuya función es la libre formación de la opinión, la cual hace al individuo responsable y libre desde el momento en que le proporciona los elementos necesarios para su autodeterminación. $\mathrm{Y}$, al mismo tiempo, le 
suministra también los conocimientos necesarios para poder enjuiciar a los Gobiernos y votar en consecuencia con pleno juicio en los procesos electorales $^{21}$. Pero evidentemente sólo puede existir una libre formación de la opinión si está vigente un pluralismo informativo al que todos puedan tener acceso. Los medios plurales poseen así una función emancipadora como vehículos que transmiten la información necesaria para que cada ciudadano pueda tomar, contrastando las diversas informaciones, sus propias decisiones. Sin embargo, tan importante función desaparecería con una concentración abusiva de los medios.

$Y$, por otra parte, se llegasen a crear unos oligopolios informativos, en manos de poderosos multimedia, cambiaría el carácter de los mismos, hasta el punto de que ya no sería válido el esquema que he expuesto hasta aquí. En efecto, ya no cabría hablar, en sentido estricto, del "janismo" de los medios o, mejor dicho, habría que aludir a otro tipo de «janismo". Porque entonces se produciría una especie de «berlusconización» de la política, en donde los propietarios de los medios ejercerían su enorme poder político sobre dos frentes: sobre el propio Gobierno y sobre los ciudadanos, convirtiéndose ambos en títeres del nuevo Big Brother al que se refería ORWELL. Pero eso es ya otra historia y requeriría otra exposición

\section{CONCLUSIÓN}

En conclusión: el derecho a la información, pilar básico de toda moderna democracia, estriba en la posibilidad de que cada ciudadano pueda acceder al conocimiento de todo lo que afecta a la cosa pública. $\mathrm{O}$, como señala ALFRED SAUVY, hay que convenir en que "el problema esencial de una sociedad que quiere ser democrática radica en saber cómo son informados los ciudadanos y cómo deberían serlo» ${ }^{22}$.

A una y otra de estas preguntas he tratado de responder a lo largo de esta exposición que ha partido del carácter híbrido de los medios de comunicación en nuestras actuales sociedades, en las que existe una estrecha correlación entre información, poder y riqueza, acentuada incluso

21 Cfr. SaAvedra, M., "Etica televisiva y derechos del público», Claves, julio-agosto de 1994, pág. 44.

${ }_{22}$ SAuVy, A., La naturaleza social, Taurus, Madrid, 1962, pág. 352. 
por la creciente internacionalización que conduce más y más a la «aldea global» de que hablaba MACLUHAN.

No sorprende, desde tal perspectiva, que un ilustre periodista francés, director de LE MONDE, haya sostenido recientemente que el régimen telecrático que se está ensayando actualmente en la Italia de Berlusconi aparece como un grave riesgo respecto al ejercicio de los poderes. La televización del poder - por utilizar un término fletado por JIMÉNEZ DE PARGA ${ }^{23}$ según la opinión del periodista francés, no hace sino acentuar la acuciante necesidad de que aparezca en Europa un nuevo MONTESQUIEU, capaz de teorizar sobre un nuevo equilibrio de los poderes que permita preservar la democracia.

En espera de que llegue pronto este nuevo Barón de Secondat, la mejor manera de garantizar la supervivencia de los regímenes democráticos, pasa por la existencia de medios de comunicación independientes que puedan ejercer un control del poder político. Porque, en definitiva, la función de la prensa libre no consiste en reflejar la luz del sol, sino en iluminar las zonas oscuras y sinuosas a las que tan aficionado es todo poder político. 